\title{
Magnana, a new genus of Gyponini from Southeastern Brazil (Hemiptera: Cicadellidae: lassinae)
}

\author{
Alexandre Cruz Domahovski ${ }^{1,2}$ \& Rodney Ramiro Cavichioli ${ }^{1,3}$ \\ 1 Universidade Federal do Paraná (UFPR), Setor de Ciências Biológicas, Departamento de Zoologia (DZ00). Curitiba, PR, Brasil. \\ ${ }^{2}$ ORCID: http://orcid.org/0000-0003-4588-4236. E-mail: domahovskiac@yahoo.com.br \\ ${ }^{3}$ ORCID: http://orcid.org/0000-0001-5996-0629. E-mail: cavich@ufpr.br
}

\begin{abstract}
A new leafhopper genus in the tribe Gyponini is proposed based on Magnana splendida gen. nov. et sp. nov., from the state of Rio de Janeiro, Brazil. Representatives of the new genus differ from other genera in the tribe mainly by the large body size, the narrow head, moderately produced anterad, the rugose crown and frons, the ventral surface of metatarsomere I with two double rows of setae, and the aedeagus bearing atrial processes. Detailed descriptions and illustrations are provided, as well as remarks on the morphology of other gyponine genera.
\end{abstract}

Keywords. Auchenorrhyncha; lassinae; Neotropical region; Taxonomy.

\section{INTRODUCTION}

lassinae Walker, 1870 is one of the most diverse subfamilies of Cicadellidae, including more than 2,000 species and 170 genera distributed worldwide, which are currently classified into 12 tribes (Krishnankutty et al., 2016; Domahovski, 2020).

Gyponini Stål, 1870, whose representatives are restricted to the New World, is a well-supported monophyletic tribe, considered as sister group to the Caribbean genus Lipokrisna Freytag 2012 (lassinae: Lipokrisnini) (Krishnankutty et al., 2016). Members of Gyponini and Lipokrisna are thought to have diverged around $100 \mathrm{Ma}$ and diversified in the Neotropical region after the separation of Africa from South America (Engel \& Takiya, 2012; Krishnankutty et al., 2016). Dispersal into the Nearctic region probably occurred after the rise of the Panamanian isthmus during the Eocene period (Nielson \& Knight, 2000).

Gyponini currently comprises 1,404 species in 70 genera, encompassing most of the species diversity in lassinae (Domahovski et al., 2020; Domahovski \& Cavichioli, 2020; Freytag, 2020). However, the Neotropical iassine fauna and its host plants remain poorly known (Dai \& Dietrich, 2015; Krishnankutty et al., 2016; Domahovski, 2020). Members of this tribe can be distinguished from other iassines by the following combination of features: (1) ocelli on crown, distant from head margin; (2) head often produced anteriorly with well delimited crown-face transition; and (3) hind wing with veins $R_{4+5}$ and $M_{1+2}$ free (Dietrich, 2005; Krishnankutty et al., 2016). Specimens are mostly collected with the aid of sweeping nets and yellow plates, however, Malaise and light traps are the most effective methods for sampling these insects (Domahovski \& Cavichioli, 2018).

This paper aims to describe a new genus of Gyponini, based on Magnana splendida gen. nov. et sp. nov. from the state of Rio de Janeiro, Brazil.

\section{MATERIAL AND METHODS}

The specimen studied is deposited in the Coleção Entomológica Pe. Jesus Santiago Moure, Universidade Federal do Paraná, Curitiba, Brazil (DZUP).

Terminology mainly follows Young (1968, 1977), except for head features (Hamilton, 1981; Mejdalani, 1998), wings (Dietrich, 2005), and leg chaetotaxy (Rakitov, 1997). Techniques used for the dissection of the male genitalia follow Oman (1949), with a few modifications described by Cavichioli \& Takiya (2012). Illustrations were prepared according to the procedures described by Domahovski \& Cavichioli (2019).

Verbatim label data are transcribed between quotation marks, with a backslash ( $($ ) separating the lines on the labels. Abbreviations used in the descriptions are as follows: $A D=$ anterodorsal; $\mathrm{AV}=$ anteroventral; $\mathrm{PD}=$ posterodorsal; $\mathrm{PV}=$ posteroventral; IC = Intercalary. 


\section{RESULTS}

\section{Taxonomy}

\section{Magnana gen. nov.}

Figs. 1-17

\section{Type species: Magnana splendida sp. nov.}

Diagnosis: Large-sized and robust (Figs. 16, 17); head in dorsal view, distinctly narrower than humeral pronotal width, moderately produced anterad, crown surface strongly rugose (Figs. 1, 16); frons rugose (Fig. 2); crown-face transition distinct, slender but not foliaceous (Figs. 3, 17); appendix of forewing very narrow (Fig. 4); metatarsomere I with two double rows of setae, setae not cuculate (Fig. 5); pygofer lacking processes (Fig. 8); connective Y-shaped (Fig. 11); aedeagus bearing atrial processes (Figs. 14, 15).

Description: Large-sized and robust. Head, dorsal view (Figs. 1, 16): distinctly narrower than pronotum, transocular width seven-tenths of pronotal humeral width, moderately produced anterad, median length longer than half interocular width, anterior margin of crown subtriangular, surface strongly rugose, slightly concave near anterior margin; ocellus small-sized, approximately equidistant between median line and eye margin, and between anterior and posterior margins of crown; coronal suture indistinct. Head, ventral view (Fig. 2): face slightly wider than long; frontogenal sutures distant from eye margins by slightly less than maximum width of clypeus, surpassing antennal ledges, extended to anterior margin of crown; antennal ledge carinate, obliquely descending and slightly extended over frons; frons $1.6 \times$ longer than wide, texture rugose; epistomal suture indistinct; gena with deep striae, lateral margin excavated just below eyes, ventrolateral margin straight; maxillary plates reaching apex of clypeus; lora striate and rugose; clypeus $1.3 \times$ longer than its maximum width, lateral margins parallel, apex straight and carinated. Head, lateral view (Figs. 3, 17): crown-face transition distinct, slender but not foliaceous, irregular striae laterally, middle portion smooth; frons and clypeus not inflated.

Pronotum, dorsal view (Fig. 1): deep transverse striae on disc and posterior half, anterior portion rugose; lateral margins long, $1.5 \times$ longer than eye length, carinate and convergent anterad; anterior margin broadly round; posterior margin excavated; lateral view (Fig. 3): moderately declivous, head and pronotum in continuous slope; proepimeron with transverse striae. Mesonotum, dorsal view (Fig. 1): longer than wide, rugose, lateral angles shagreen; scutellum flat in lateral view (Fig. 3).

Forewing opaque, wide, $2.7 \times$ longer than maximum width (Fig. 4); venation distinct, extra cross-veins or veinlets absent; texture finely rugose; three anteapical cells and five apical, vein R1 present; appendix very narrow.

Profemur: $A D, A M$ and $P D$ rows reduced and poorly defined, except for apical setae $A D_{1}, A M_{1}$ and $P D_{1}$, respec- tively; AV and PV including 3-4 and 3 setae respectively; IC row formed by slightly arched comb of fine setae, from distal third of femur to $\mathrm{AM}_{1}$. Protibia: dorsal surface concave, round longitudinal carina adjacent to PD row; AV row formed by short setae, slightly longer and thicker toward apex, apical setae shorter than maximum diameter of protibia; $A D$ and $P D$ rows formed by undifferentiated setae, bearing few slightly longer and thicker intercalary setae; PV row with 7 longer setae intercalated by undifferentiated setae. Hind leg femoral setal formula 2:2:1. Metatibia: $A D$ row lacking intercalary setae between macrosetae; PD, AD and AV rows bearing 20, 12 and 16 macrosetae, respectively. Metatarsomere I (Fig. 5): two double rows of setae, base not cucullate; apex with 6 platellae. Metatarsomere II (Fig. 5): apex with 4 platellae.

Male terminalia: Pygofer (Fig. 8) lacking processes. Connective Y-shaped (Fig. 11). Aedeagus bearing atrial processes (Figs. 14, 15).

Female: Unknown.

Etymology: The generic name Magnana (feminine noun) is derived from the Latin word "magnus" meaning great or large. It refers to the fact this is one of the largest leafhoppers presently recorded for the tribe Gyponini. The suffix - ana is common in Gyponini genus names.

Distribution: Rio de Janeiro, Brazil.

Notes: As noted in the genus diagnosis, Magnana gen. nov. exhibits a singular combination of morphological features which readily separates this group from other genera in the tribe. Magnana gen. nov. shares a few traits with Declivara DeLong \& Freytag, 1971 and Flexana DeLong \& Freytag, 1971, such as: a large body; a rugose crown; a very narrow forewing appendix; and atrial processes in the aedeagus. However, Magnana gen. nov. differs in having a much narrower head as compared to the humeral width of pronotum; crown moderately produced anterad; crown-face transition distinct and slender; slightly declivorous pronotum; forewing lacking extra cross-veins; first tarsomere with two double rows of simple setae on ventral surface; and processes absent in the pygofer. In contrast, Declivara and Flexana have a distinctly wide head; short crown, not produced; crown-face transition indistinct and thick; pronotum strongly declivous; forewing with extra cross-veins; first tarsomere with two simple rows of cucullate setae; and pygofer bearing processes.

Despite the similarities between these genera, their phylogenetic relationship still needs to be investigated based on morphological and/or molecular data.

\section{Magnana splendida sp. nov. Figs. 1-17}

Diagnosis: Inner margin of pygofer (Fig. 9) serrated apically; style (Fig. 13) elongated and sigmoid; shaft of ae- 

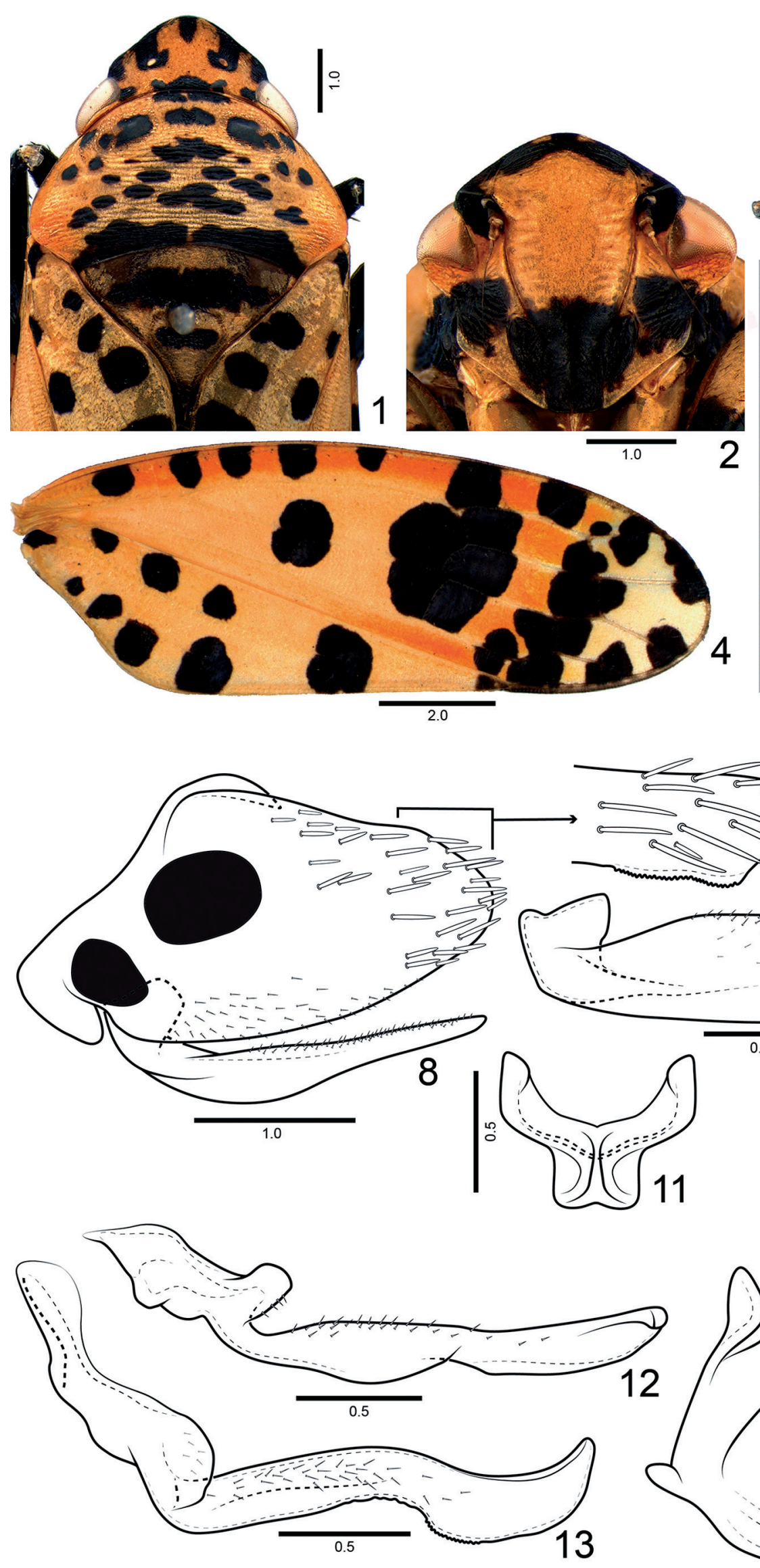

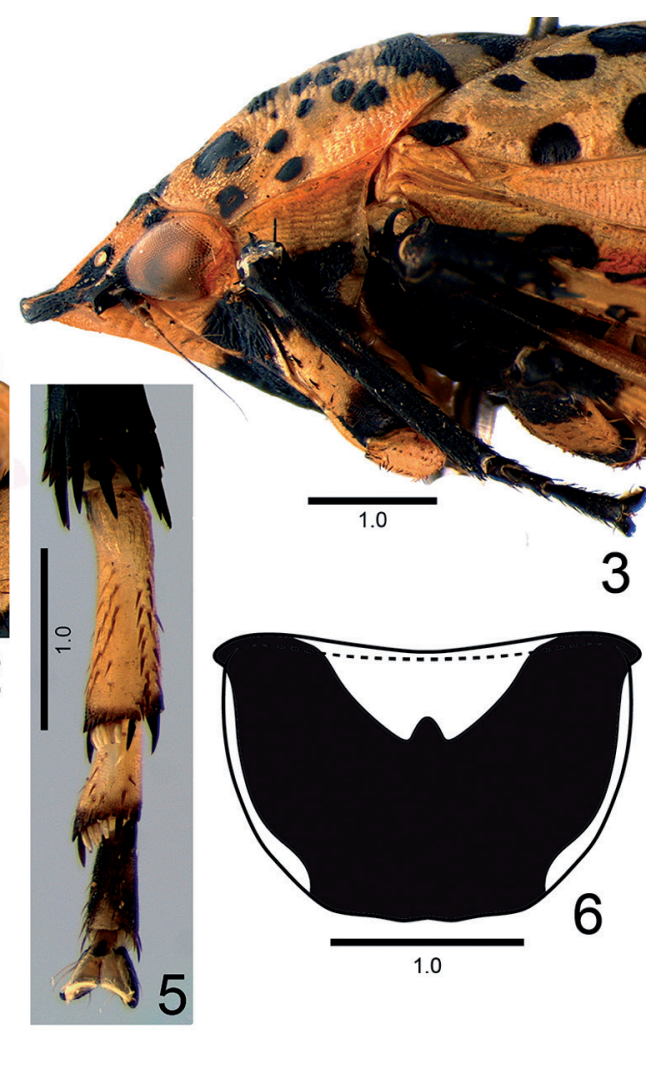

Figures 1-15. Magnana splendida sp. nov., holotype male. (1) head and thorax, dorsal view. (2) head, ventral view. (3) head and thorax, lateral view. (4) forewing. (5) metatarsus, ventral view. (6) sternite VIII, ventral view. (7) valve, ventral view. (8) pygofer, valve and subgenital plate, lateral view. (9) Enlarged view of apical portion of pygofer, dorsal view. (10) subgenital plate, ventral view. (11) connective, dorsal view. (12) style, dorsal view. (13) style, lateral view. (14) aedeagus, lateral view. (15) aedeagus, posterior view. 
deagus (Figs. 14, 15) bearing one short subapical process on anterior surface, curved ventrally, with pair of apical processes, slightly longer, branched at apex, branches directed ventrally.

Type locality: Nova Friburgo, Rio de Janeiro, Brazil.

Measurements (mm): Total length: 18.7; head length: 1.4; transocular width: 3.6; humeral width of pronotum: 5.0; forewing length: 12.0; forewing width: 4.2.

Color: Mostly yellow (Figs. 16, 17). Crown (Fig. 1) with black maculae on following areas: posterior margin, behind ocelli; inner margin of eyes, surrounding ocelli and extending to anterior margin; and apex of anterior margin. Pronotum (Fig. 1): several large round black maculae on disc and anterior portion; posterior margin with transverse irregular-shape black macula. Mesonotum and scutellum (Fig. 1) with transverse black macula. Face (Fig. 2): transition crown-face black; area surround- ing antenal pits black; gena with large black spots medially; ventral portion of frons, lora and clypeus black. Proepimeron (Fig. 3) with ventral half black. Forewing (Fig. 4) with several large black maculae; costal margin orange. Profemur (Fig. 3) with base and apex black. Protibia (Fig. 3) and protarsus black. Mesofemur and mesotibia (Fig. 17) with base and apex black. Mesotarsus black. Metafemur and metatibia (Figs. 16, 17) with base and apex black. Metatarsus (Fig. 5) with third tarsomere black. Abdomen with dorsal portion black; sternite III almost entire black; sternites IV-VII with pair of black maculae on anterolateral angles; sternite VIII (Fig. 6) almost entire black, anterior and lateral margins yellow. Pygofer (Fig. 8) with two black spots on anterior portion.

Description: External morphological characters as in generic description.

Male terminalia: Sternite VIII (Fig. 5), in ventral view, $1.5 \times$ wider than long; lateral margins slightly round-

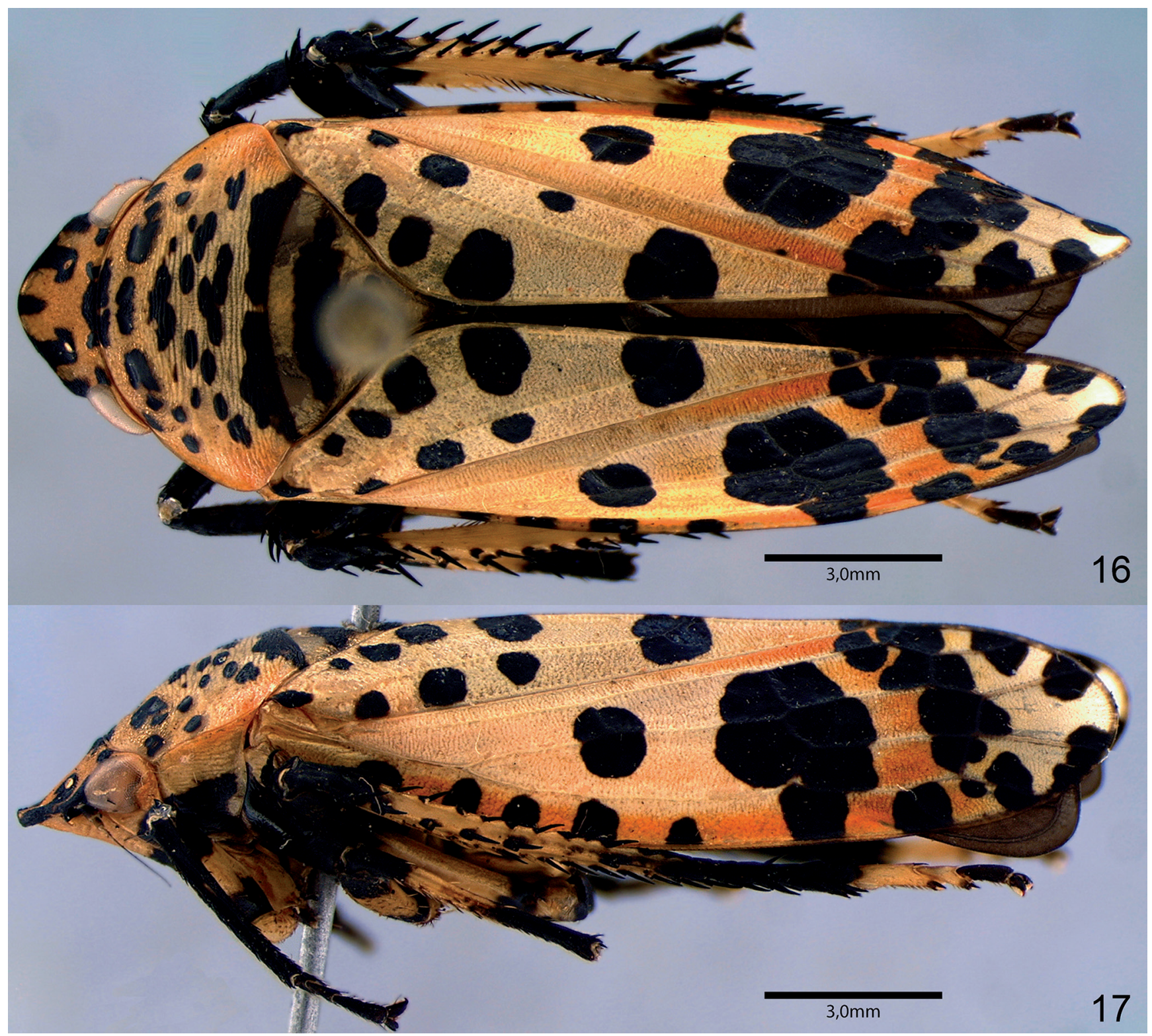

Figures 16-17. Magnana splendida sp. nov., holotype male, habitus. (16) dorsal view. (17) lateral view. 
ed and convergent posterad; posterior margin slightly undulated. Valve (Fig. 7), in ventral view, $2 \times$ wider than long; integument thickened on anterior margin only; posterior margin notched medially. Pygofer (Fig. 8), in lateral view, 1.8x longer than maximum height; ventral margin broadly round, bearing small setae; apex slightly tapered and round; macrosetae dispersed near apex and dorsal margin; in dorsal view (Fig. 9), apical portion of inner margin finely serrated, but not produced into process. Subgenital plate (Fig. 8), in lateral view, produced posteriorly almost as far as pygofer apex; in ventral view (Fig. 10), elongated, $4.5 \times$ longer than wide; lateral margins approximately straight; external margin and ventral surface bearing short setae; apex round. Connective (Fig. 11), in dorsal view, stalk present, wider than long; arms curved anterad, dorsal keel small. Style (Fig. 12), in dorsal view, with outer lobe well-developed, round; in lateral view (Fig. 13), blade elongated and sigmoid; external surface bearing small setae except on apical portion; apical portion with ventral margin serrated; apex slightly curved dorsally. Aedeagus (Figs. 14, 15) with preatrium reduced; dorsal apodeme not expanded laterally; atrial processes with dorsal and ventral margins almost parallel; apex tapered and rounded, curved inwards; shaft tubular and elongated, curved dorsally near base and straight distally; apex with one short subapical process on anterior surface, curved ventrally, and pair of slightly longer apical processes, with branched apex, directed ventrally.

Female: unknown.

Etymology: The specific epithet refers to the singular beauty of this leafhopper.

Material examined: Holotype male:"RJ. Nova Friburgol Sans Souci 05.V.09\ E.J. Grossi col. Luz" (DZUP).

\section{ACKNOWLEDGEMENTS}

The authors thank the Conselho Nacional de Desenvolvimento Científico e Tecnológico for the financial support provided to A.C. Domahovski (CNPq 140815/2017-1). Many thanks to the editorial team of the Papéis Avulsos de Zoologia and two anonymous reviewers who offered their comments on an earlier version of this manuscript.

\section{AUTHORS' CONTRUBUTIONS}

A.C.D. dissected and identified the specimen; A.C.D. and R.R.C. wrote the text; A.C.D. made the images; R.R.C. revised the text.

\section{REFERENCES}

Cavichioli, R.R. \& Takiya, D.M. 2012. Description of a new species of Wolfniana and new records of Rotigonalia (Hemiptera: Cicadellidae: Cicadellinae) from the state of Amazonas, Brazil. Zoologia, Curitiba, 29(1): 85-88.

Dai, W. \& Dietrich, C.H. 2015. A new genus of lassinae (Hemiptera: (icadellidae) from Peru and a new species of Daveyoungana Blocker \& Webb. Zootaxa, 3946(2): 285-295.

Dietrich, C.H. 2005. Keys to the families of Cicadomorpha and subfamilies and tribes of Cicadellidae (Hemiptera: Auchenorrhyncha). Florida Entomologist, 88(4): 502-517.

Domahovski, A.C. 2020. New species of Bertawolia Blocker and Momoria Blocker (Cicadellidae: lassinae: Hyalojassini) from Brazil, including notes about host plants. Zootaxa, 4808(3): 475-490.

Domahovski, A.C. \& Cavichioli, R.R. 2018. Two new remarkable genera and two new species of Gyponini (Hemiptera: Cicadellidae: lassinae) from Brazil. European Journal of Taxonomy, 476: 1-17.

Domahovski, A.C. \& Cavichioli, R.R. 2019. Three new species of Daveyoungana Blocker \& Webb (Hemiptera: Cicadellidae: lassinae: Hyalojassini) from Brazil. Zootaxa, 4571(4): 477-488.

Domahovski, A.C. \& Cavichioli, R.R. 2020. Three new species of Polana (Varpulana) (Hemiptera: Cicadellidae: Gyponini) from Brazil, with updated key to males and taxonomic notes on the female genitalia. Zootaxa, 4767(4): 501-517.

Domahovski, A.C.; Gonçalves C.C.; Takiya, D.M. \& Cavichioli, R.R. 2020. Description of two new species of Regalana and a new genus of Gyponini (Hemiptera: Cicadellidade: lassinae). Zootaxa, 4731(1): 89-102.

Engel, G. \& Takiya, D.M. 2012. Synopsis of Clinonana Osborn (Hemiptera: (icadellidae: lassinae): new distributional records and description of a new species. Zootaxa, 3329(1): 19-30.

Freytag, P.H. 2020. A New Species of Acusana from French Guiana (Hemiptera: (icadellidae: Gyponinae). Entomological News, 129(1): 1-5.

Hamilton, K.G.A. 1981. Morphology and evolution of the Rhynchotan head (Insecta: Hemiptera, Homoptera). Canadian Entomologist, 113(11): 953-974.

Krishnankutty, S.M.; Dietrich, C.H.; Dai, W. \& Siddappaji, M.H. 2016. Phylogeny and historical biogeography of leafhopper subfamily lassinae (Hemiptera: Cicadellidae) with a revised tribal classification based on morphological and molecular data. Systematic Entomology, 41(3): 580-595.

Mejdalani, G. 1998. Morfologia externa dos Cicadellinae (Homoptera, Cicadellidae): comparação entre Versigonalia ruficauda (Walker) (Cicadellini) e Tretogonia cribrata Melichar (Proconiini), com notas sobre outras espécies e análise da terminologia. Revista Brasileira de Zoologia, 15(2): 451-544.

Nielson, M.W. \& Knight, W.J. 2000. Distributional patterns and possible origin of Leafhoppers (Homoptera, Cicadellidae). Revista Brasileira de Zoologia, 17: $81-156$

Oman, P.W. 1949. The Nearctic leafhoppers (Homoptera: Cicadellidae). A generic classification and check list. Memoirs of the Entomological Society of Washington, 3: 1-253.

Rakitov, R.A. 1997. On differentiation of cicadellid leg chaetotaxy (Homoptera: Auchenorrhyncha: Membracoidea). Russian Entomological Journal, 6: 7-27.

Young, D.A. 1968. Taxonomic study of the Cicadellinae (Homoptera: (icadellidae), Part 1, Proconiini. Bulletin of the United States National Museum, 261: 1-287.

Young, D.A. 1977. Taxonomic study of the Cicadellinae (Homoptera: Cicadellidae). Part 2. New World Cicadellini and the genus Cicadella. Bulletin of North Carolina Agricultural Experiment Station, 239: 1-1135. 